\title{
Urodimento
}

REVISTA DE ESTUDOS EM ARTES CÊNICAS

E-ISSN 2358.6958

\section{A primeira onda da cena travesti no Brasil: A centralidade do "corpo em travesti"}

\author{
Djalma Thürler
}

Beatrice Mathieu

Para citar este artigo:

THÜRLER, Djalma; MATHIEU, Beatrice. A primeira onda da cena travesti no Brasil: A centralidade do "corpo em travesti”. Urdimento - Revista de Estudos em Artes Cênicas, Florianópolis, v. 2, n. 41, set. 2021.

doi DOI: http:/dx.doi.org/10.5965/1414573102412021e0102

Este artigo passou pelo Plagiarism Detection Software | iThenticate 


\title{
A primeira onda da cena travesti no Brasil: A centralidade do "corpo em travesti"
}

\author{
Djalma Thürler ${ }^{1}$
}

Beatrice Mathieu²

\begin{abstract}
Resumo
O ensaio interdisciplinar entende a "cena travesti" no Brasil enquanto estética travesti, prática profissional do travestismo, distante das questões identitárias e propõe a divisão desta cena em quatro ondas, fases, movimentos. Baseado nos estudos sobre o Teatro e a História, as autoras se debruçam sobre a primeira onda travesti de onde extraem relevantes características estéticas do Teatro de Revista que irão refletir, seja na segunda onda, seja no entendimento de gênero enquanto construção, invenção social normativa.
\end{abstract}

Palavras-chave: Cena travesti. Teatro brasileiro. Aymond. Ivaná.

\section{The first wave of the transvestite scene in Brazil: The centrality of the "transvestite body"}

\begin{abstract}
The interdisciplinary essay understands the "transvestite scene" in Brazil as transvestite aesthetics, professional practice of transvestism, away from identity issues and proposes the division of this scene into four waves, phases, movements. Based on studies on Theatre, History and Queer Theory, the authors focus on the first wave from where they extract relevant aesthetic characteristics that will reflect, above all, in the second wave.
\end{abstract}

Keywords: Transvestite scene. Brazilian theater. Aymond. Ivaná.

${ }^{1}$ Pós-Doutoramento em Literatura e Crítica Literária na Pontifícia Universidade Católica (PUC/SP). Doutorado em Letras com estudos nas áreas de Literatura Brasileira e Teatro pela Universidade Federal Fluminense (UFF). Mestrado em Ciência da Arte (UFF). Bacharel em Artes Cênicas e em Pedagogia, pela Universidade Federal do Estado do Rio de Janeiro (UNIRIO). Professor permanente do Programa Multidisciplinar de PósGraduação em Cultura e Sociedade e Professor Associado III do Instituto de Humanidades, Artes e Ciências (IHAC) da Universidade Federal da Bahia (UFBA). djalmathurler@uol.com.br

(9) http://lattes.cnpq.br/5632978212911927 (iD https://orcid.org/0000-0002-9161-0300

${ }^{2}$ Mestranda do Programa Interdisciplinar em Cultura e Sociedade na Universidade Federal da Bahia (UFBA). Artista da cena travesti. beatrice.matie@gmail.com

(9) http://lattes.cnpq.br/8550401945974290 (iD https://orcid.org/0000-0001-7679-8862 
la primera ola de la escena travesti en Brasil:

La centralidad del "cuerpo travestido"

\section{Resumen}

El ensayo interdisciplinario entiende la "escena travesti" en Brasil como una estética travesti, una práctica profesional del travestismo, lejos de las cuestiones de identidad y propone la división de esta escena en cuatro ondas, fases, movimientos. Basándose en los estudios sobre Teatro, Historia y Teoría Queer, los autores se centran en la primera ola de la que extraen características estéticas relevantes que se reflejarán, sobre todo, en la segunda ola.

Palabras clave: Escena de travestis. Teatro brasileño. Aymond. Ivaná. 


\section{Apresentação}

Ao discutir sobre a ideia da existência de uma cena travesti, queremos resgatar alguns aspectos já apresentados em outros textos (Trevisan, 2007; Meneses, Jayo, 2018) e filmes, como Divinas Divas(2017), Lampião da Esquina (2016), São Paulo em Hi Fi(2013), Dzi Croquettes(2009) e Meu amigo Cláudia (2009), para constatar, em primeiro plano, a existência de uma transhistória a partir da enunciação de uma cena travesti no Brasil, tão instável quanto potente, a partir de quatro fases contextualizadas em acontecimentos políticos, econômicos, sociais e culturais. Na carona de Facchini (2005), utilizaremos a metáfora da "onda" para designar as etapas dessa cena travesti, de alguma forma já delineada por Trevisan (2007) e por Emerson Silva Meneses e Martin Jayo (2018). Em um segundo plano, ressaltamos a potência dessa cena em travesti para reforçar a ideia de invenção de natureza, defendida por Rita Segato (2018).

Se concordarmos com Ivaná ${ }^{3}$ (1953), para quem a primeira travesti do teatro brasileiro foi Aymond ${ }^{4}$, damos os primeiros passos para entender a cena travesti, tal como a entendemos, não vinculada à ideia de uma "identidade social, independente de trajetórias profissionais, localizando sujeitos políticos com demandas sociais identificáveis a partir da vivencia de uma identidade de gênero especifica” (Bortolozzi, 2015, p.125). Aliás, a própria Ivaná era uma artista "transformista, identificada pela mídia da época como uma travesti que atuava em peças teatrais nas companhias de Walter Pinto e Zilco Ribeiro" (Lion, 2015, p. 104). Ou seja, travesti era o adjetivo que qualificava uma determinada cena artística que teve inúmeras variações durante a história, mas marcada profundamente pelo travestismo do ator que, independente se sua orientação sexual, performava uma personagem feminina, ou seja, "[...] hoje em dia a palavra travesti é usada indiscriminadamente, de modo que o que ela diz é que alguém está a travestir. Em suma, diz o que ele FAZ, não o que ele É" 5 .

3 Ivaná é a personagem criada pelo ator Yvan Monteiro Damião nos anos 1950.

${ }^{4}$ Personagem de Norberto Américo Aymonino.

${ }^{5}[. .$.$] today the word transvestite is used indescriminately so that what it says is that someone is crossdressing.$ 
A expressão travestiem nosso título - cena travesti -, então, "estaria[m], na realidade, próxima[s] da arte drag queen, no entanto, não seria[m] ainda como a contemporânea drag de hoje” (Lion, 2016, p.6). Para Letícia Lanz, o corpo travestido converte-se em campo aberto para infinitas possibilidades de expressão do sujeito (Lanz, 2014) e, nesse caso, o desempenho em palco seria fundamental para distinguir a identidade social travesti dos "travestis-atores" (Trevisan, 2007, p. 243), cujo travestismo se limita normalmente ao contexto do show ou da performance teatral. Para Morando (2020), “tornou-se muito comum a expressão 'fazer travesti' como forma de se referir ao travestimento de 'homens como se fossem mulheres'. Foi uma fórmula empregada por diversas produções discursivas, particularmente nas artes visuais, especialmente no teatro" (Morando, 2020, p.47).

Apesar da tentativa de delimitar o que queremos fazer entender por "cena travesti”, concordamos com Bortolozzi (2015) que reconhece que, apesar de esforços na tentativa de uma construção de categorias que identifiquem e classifiquem diferentes subjetividades e práticas culturais ligadas ao travestismo, no Brasil, "esse arcabouço conceitual nunca conseguiu contemplar a complexidade do uso de termos como 'travesti', 'transexual' e 'transformista'” (Bortolozzi, 2015, p.126), pois há muitas divergências de pareceres, teorias, estudos e opiniões ${ }^{6}$ e, parece, não foi diferente no contexto dos países hispânicos:

Vocablos como transexual, travestí, transgénero, trans, trans*, travelo, hermafrodita, intersexual, entre otros, surgen en momentos históricos determinados, con diferentes cosmovisiones que dan el significado a las rupturas con el sexo asignado en el nacimiento, la expresión, corporalidad o identidad de una persona. Una historia y una terminología que hemos de entender con la distancia y la necesidad de reconocer que no tienen la misma trayectoria y enraizamiento que em lugares de habla hispana (Platero, 2017, p.9).

In short it says what he DOES, not what he IS. (Tradução nossa)

${ }^{6}$ Em 14 de dezembro de 2020, o Jornal Correio, de Salvador, publicou matéria intitulada "UFSB cancela matrícula de estudante de Medicina por suspeita de fraude na cota para trans: "me mataram”. Na matéria, Jô ou Joana, como também se identifica, "questionou a postura da instituição, que não houve transparência no processo nem Justiça na decisão de cancelar a matrícula. "Não respeitaram minha identidade de gênero. Decidiram a qualquer custo que iriam me tirar de lá. A UFSB me destrói, mas isso tudo só serviu para me libertar das amarras da sociedade machista e transfóbica. Eles definiram que eu seria um 'judas para dar exemplo', mas não se preocuparam com o lado humano. Em nenhum momento do processo a UFSB deixou claro que bases usaram para definir minha transgeneridade ou não. Foi um processo injusto", destacou Joana (Gaultier, 2020, s/p). 
Desse modo, não podemos afirmar com segurança que os artistas aqui destacados se sentiam a si próprios ou eram percebidos pelas suas sociedades como não conformes com o gênero, mas apesar dessa dificuldade, reiteramos que, nesse trabalho, as presenças de Aymond nos palcos brasileiros entre os anos 1920 e 1930 e de Ivaná, entre 1950 e 1960, como artistas transformistas, delimitam a primeira onda da cena travesti, tendo como características fundamentais, a imitação de mulheres e o legado estético e discursivo do Teatro de Revista, que antecederia a explosão desses espetáculos, a partir de 1960.

O boom da cena travesti, a segunda onda, que remonta às produções dos anos 1960 a 1980 até a chegada da AIDS, corresponde, concomitante, à explosão da homossexualidade no país e a consequente expansão da "sociedade bichal". É nesse período que "essa memória 'proibida' e, portanto, 'clandestina' ocupa toda a cena cultural, o setor editorial, os meios de comunicação, o cinema e a pintura" (Pollak, 1989, p.5). Figari (2007), em sua pesquisa sobre a década de 60 no Rio de Janeiro destaca que

foi possível documentar o surgimento dos shows de transformismo que fizeram moda na cidade nas décadas seguintes e criaram oportunidades para a emergência de inúmeros talentos artísticos 'de cinema e teatro', que conquistaram o reconhecimento público e crítico para além da subcultura homófila (Figari, 2007, p. 387).

A terceira onda de 1990 a 2009, é marcada profundamente pela estética drag queen pré-RuPaul's Drag Race. Para Lucas Bragança, a expressão drag queen, chega o Brasil em meados da década de 90 "e passou a delimitar mais homens gays que performavam nas casas noturnas” (Bragança, 2018, p. 24-25). Isso já vinha ocorrendo desde a década de 1970, em casos raros como o do transformista Laura de Vison - durante o dia, um pacato professor de História e, à noite, um animador de shows frenéticos, em boates gueis - ou, já dentro de uma prática mais ampla e comum, nos anos 90, como é o caso da drag queen

Kaká di Polli, por exemplo, [que trabalhava] durante o dia como psicólogo, na área de sexualidade. A atuação das drag queens foi facilitada por englobar um componente lúdico e satírico semelhante ao das caricatas do carnaval, o que as levou a transitar por áreas jamais imaginadas, como as concorridas festas de socialites, shows beneficentes e colunas sociais da grande imprensa (Trevisan, 2007). 
A partir da estreia do Programa RuPaul's Drag Race, em 2009, apresentado por uma das mais aclamadas e politicamente identificáveis drag queens nos Estados Unidos, acusamos o início da quarta onda, marcada pelo uso de componentes estéticos do low camp, que imprimiu ao drag uma nova referência entre a comunidade LGBT+, como, também ampliou seu alcance para fora do seu círculo de sociabilidade original, se aproximando da ideia de drags satélites, aquelas que "potencializam, em torno de si e do seu trabalho artístico, recursos econômicos, sociais e culturais" (Thürler; Nunes; Romero, 2016, p.216) se projetando, midiaticamente, de forma mais ampla e articulada.

O trabalho de Meneses e Jayo (2018), já citado, também desenvolve "uma periodização para a presença travesti nos palcos brasileiros, apontando uma 'pré-história' e quatro fases para esse fenômeno" (Meneses; Jayo, 2018, p.160) que estabelecem recortes temporais e entendimentos diferentes dos que aqui queremos delinear. Do modo como queremos fazer entender, não é a presença travesti que estabeleceria uma "cena travesti", mas sim, seus elementos estéticos. De agora em diante, começamos a falar sobre a primeira onda.

\section{Entre telões e cortinas}

O Teatro de Revista brasileiro, segundo Neyde Veneziano (1994), é um teatro popular, nascido nos teatros de feiras e, em sua "forma estrutural francesa" (Veneziano, 1994, p. 142), tornou-se um instrumento popular para informar e refletir sobre os eventos que então se realizavam em França. Um tipo específico de teatro começou a aparecer, a chamada revue de fin d'année, que foi utilizada para contar, mostrar e comentar os principais acontecimentos políticos e sociais do ano anterior. Primeiro,

os cômicos populares começam a montar espetáculos que passam em revista os principais acontecimentos teatrais do ano. Parodiavam, com o deboche e o escracho que se tornariam marcas do gênero, os grandes autores dramáticos em voga - Marivaux, Corneille, Racine. Com o passar do tempo, e por causa do grande sucesso de público, não somente os fatos teatrais, mas os principais acontecimentos do ano são revistos. A revista rapidamente sai da França e alcança popularidade em outros 
países da Europa (Marques, 2001, p.42).

Com uma combinação de canções populares, humor e atualidade, a revue de fin d'année tornou-se um grande sucesso popular porque satisfazia as necessidades de entretenimento e informação do público em geral e espalhou-se rapidamente por toda a Europa, tendo chagado à Portugal em meados do século XIX, segundo Luiz Francisco Rebello (1984), com Lisboa em 1850, que estrearia a 11 de janeiro de 1851, no Teatro do Ginásio. O sucesso da empreitada garantiu que a revue de fin d'année rapidamente deixasse de ser apenas um evento anual para tornar-se um empreendimento comercialmente bem sucedida, o que aconteceu através de várias produções e, também, se espalhando pelo mundo.

No Brasil, esse formato vai se chamar Revista de Ano e "funcionaria com a mesma estrutura das francesas e portuguesas" (Veneziano, 1994, p.146) e pode ser dividida em três fases.

A primeira, que teve seu inicio em 1859, vai alcançar seu auge com as peças de Arthur Azevedo, que acedia, sem resistências, às exigências do espectador médio urbano:

O espectador médio daquele tempo, como vivia a repetir Machado de Assis, amava as coisas que o alegravam. E alegrava-se com mais entusiasmo ainda ao identificar pedaços de seu cotidiano em espetáculos que procuravam conciliar o vaudeville e a opereta, numa alquimia que, sob a designação de teatro de revista, conheceu um século de consagração praticamente ininterrupta (Augusto, 1989, p.26).

Embalada por "marchas, jongos e lundus" (Augusto, 1989, p.26), a revista nessa fase é marcada, sobretudo, pela crítica social feita através de personagenstipo, aqueles, como aponta Freitas (2015, p. 121): "que representam máscaras sociais e caricaturas de personagens da atualidade"; "políticos corruptos, agiotas implacáveis, malandros cativantes ["tiranizados por credores, patrões, bandidos e megeras domésticas" (Augusto, 1989, p. 70)], casais românticos e jornalistas matreiros eram o destaque da sua fauna" (Augusto, 1989, p. 26). As Revistas de Ano tinham uma estrutura dramatúrgica muito específica e estável. Normalmente, cada peça era dividida em duas partes, cada uma com uma específica, embora 
amplo, tema. A primeira parte abriria com uma peça orquestral seguida da primeira canção. Depois, várias cenas diferentes teriam lugar, misturando canções, dançando e cenas teatrais inspiradas por eventos políticos, sociais ou teatrais, ou cenas combinando tudo isto. Estas cenas poderiam ser ligadas pela personagem do compére, um ator ou atriz que, entre as cenas, caminharia para o proscênio e, enquanto o cenário estava a ser mudado atrás da cortina, teria um diálogo crítico e humorístico com o público ou com outro ator, assim criando uma ponte temática entre as cenas. Era ele "quem dava unidade à Revista. Quando havia uma dupla de compadres ${ }^{7}$, então eles funcionavam como uma dupla de Tony e Clown ou como um primeiro e segundo zanni, ou seja, um era mais esperto e outro mais burro" (Veneziano, 1994, p.146). Depois, haveria algumas cenas de rua sobre a vida cotidiana do Rio de Janeiro, "que sempre foi o mote para estes espetáculos" (Veneziano, 1994, p.146) que terminariam com um desfile festivo, além das cenas da vedete.

A segunda fase, na década de 1920, teria duas características marcantes. Uma é variação nacional da Revista, marcada pela revista carnavalesca, essencialmente brasileira que mais tarde inspiraria os "filmes de carnaval". Segundo Sérgio Augusto, "não existe teatro popular mais espontâneo, participativo e catártico que o carnaval” (Augusto, 1989, p.73). Outra, o "estilo bataclânico" (Veneziano, 1994, p. 153), que trouxe novas influências para o gênero: desnudou o corpo feminino, despindo-o "das antigas meias grossas que as brasileiras usavam" (Veneziano, 1994, p. 153). Ainda segundo Veneziano, "na esteira do modelo Ba-ta-clan, o arrojado empresário Jardel Jércolis desviou a estética do teatro de revista para voos mais modernos e arriscados" (Veneziano, 2011, p.64). O corpo feminino das vedetes e coristas ganha mais espaço nos quadros musicais e sua valorização, agora, é reforçada, não mais como recurso coreográfico. apesar das coreografias serem "muito bem-feitas, mostrando aos brasileiros que o show bem cuidado, como parte da revista, poderia enriquecer o espetáculo" (Veneziano, 1994, p. 153), mas, também, cenográfico, através dos quadros vivos (Collaço, 2012). Enquanto que, para Veneziano (2011), "entre 1910 e 1920, a Praça Tiradentes com seu entorno 
haviam se transformado no centro revisteiro do Rio de Janeiro - por essa época, os 11 teatros da região variavam o repertório, entre revistas, burletas e operetas" (Veneziano, 2011, p.63) -, para Sérgio Augusto (1989), os teatros de Revista da Praça Tiradentes, os estúdios cinematográficos da Atlântida, na Visconde do Rio Branco, e a Rádio Nacional, na Praça Mauá, formavam "um triângulo cultural sem paralelos em nossa indústria de entretenimentos de massa” (Augusto, 1989, p.19), atravessado pela

\begin{abstract}
Avenida Central, um boulervar (sic) de dois quilômetros de extensão e 33 metros de largura ligando a Praça Mauá ao Passeio Público, onde se ergueram prédios que nada deviam em conforto e beleza arquitetônica aos de Paris e Berlim. Aí se destacavam as edificações da Casa Mauá, as sedes do Jornal do Commercio e do jornal do Brasil, a Biblioteca Nacional e o Museu de Belas-Artes, sem falar na reforma da Rua do Ouvidor e na multiplicação de sofisticadas lojas, confeitarias, cafés e serviços diversos - modistas, chapeleiros e alfaiates em dia com a moda internacional (Saroldi; Moreira, 2005, p.18).
\end{abstract}

É nesta fase que a Revista foi marcada pela existência da "rivalidade amigável" entre as primeiras estrelas de cada companhia, as vedetes, na disputa pela preferência dos espectadores.

A terceira e última fase foi a do investimento em grandes espetáculos marcados pelo imperativo absoluto do luxo, seja na cenografia e figurinos dos quadros musicais, nos efeitos visuais provocados pela iluminação e pela maquinaria, no sobe-e-desce dos telões ou pelas enormes escadarias responsáveis pelas idas e vindas das vedetes, características estéticas que se equiparavam em importância à presença das próprias estrelas. Depois dessa explosão de exuberância, o teatro de revista começa afastar a classe média, deixando de lado a comicidade e apelando para a obscenidade, o nu explícito e para o escracho. Por tudo isso, Sérgio Augusto (1989) relata que

quando, nos últimos meses de 1949, a censura apertou as cravelhas do teatro de revista carioca punindo com uma suspensão a dupla Oscarito/Dercy Gonçalves, o extemporâneo crítico teatral Oswaldo M. de Oliveira (mais conhecido como Jonald em seus fazeres cinematográficos) soltou foguetório em sua coluna: 'Finalmente teve início um movimento moralizador em volta da pornografia do teatro de revista [...] Há uma extraordinária diferença entre o subentendido e o que constantemente é 
tentado para ser impingido como tal. De um lado há sutileza e, de outro, o culto grosseiro do trocadilho, circunstância muito diferente. Agora, felizmente, a censura vem agindo' (Augusto, 1989, p.22).

Assim, a estrutura revisteira entrou em um período de colapso e decadência, praticamente desaparecendo no final dos anos 1950, se transferindo para os Night clubs, mas,

no geral, o predomínio da mediocridade engolfou todas as facetas: registrava-se a repetição monótona dos mesmos temas, das mesmas anedotas, das mesmas alegorias; músicas e rotinas testemunhavam o esgotamento dos autores; o desinteresse dos intérpretes; o mercantilismo imediatista da maioria dos empresários; o afastamento do público diante do produto espúrio que the ofereciam - mas esse afastamento tornou-se manifesto somente de meados da década em diante (Paiva, 1991, p.576-577).

No entanto, uma figura permaneceria à frente de tudo isso e se transferiria para as boates de Copacabana, "a personalidade principal do espetáculo: sua majestade, a vedete" (Veneziano, 2011, p.58).

Teatro de Revista que, por sua vez está, historicamente, vinculado ao Brasil, como o gênero mais expressivo até 1960" (Veneziano, 2011, p. 58). Sílvio de Abreu, que escreveu o roteiro de Assim era a Atlântida com Carlos Manga, em 1975, na apresentação do livro As grandes vedetes do Brasil, de Neyde Veneziano, lembra que as vedetes "brincavam com as autoridades, com os conceitos, com a moral, com a família, eram livres, soltas, destemidas, arrojadas” (Abreu, 2010, p. 14), e reverenciava: "Que corpos, que luxúria, que fantasia erótica maravilhosa foi para todos os homens essas magníficas mulheres do teatro rebolado" (Abreu, 2010, p. 14). E foram muitas. Virgínia Lane, a queridinha de Vargas e senhora absoluta das noites cariocas, Angelita Martinez, a favorita de João Goulart, Mara Rúbia, o diabo loiro, Salomé Parísio, Aracy Cortes, Nélia Paula, Iris Bruzzi, Renata Fronzi, Carmem Verônica, Marly Marley, Luz Del Fuego, Elvira Pagã, Sonia Mamede, Wilza Carla, Siwa, Brigite Blair foram algumas das mulheres mais importantes dos anos 1950 e 1960.

$\mathrm{Na}$ primeira fila do teatro, a fila do gargarejo, depois de falsificar a caderneta do ginásio, conseguir enganar o porteiro e burlar a vigilância da família, lá estava eu. Tímido, curioso, deslumbrado, à cata de um naco de perna, um vislumbre de busto e, principalmente, do envolvimento de pecado e licenciosidade que tomava conta do teatro. Assim que uma 
delas chegava ao proscênio e encarava a plateia, altiva, segura, implacável, procurando uma vítima entre nós, pobres espectadores a respiração acelerava, a adrenalina circulava por entre as poltronas. Muitas só desciam a escadaria e desfilavam seus corpos esculturais, parando em pontos estratégicos, sorrindo sensuais, convidativas; outras, mais talentosas, mais comunicativas, estabeleciam uma empatia imediata com o público. Brincavam, se divertiam, criticavam burlescamente comportamentos e políticos, longe desta praga do politicamente correto e de processos por difamação que se tem que aguentar hoje (Abreu, 2010, p.13).

Neste depoimento, Abreu se refere ao adolescente que fora na década de 1950, tempo em que, para Antunes (2002, p.124), “as grandes vedetes se tornavam musas". Segundo o depoimento do cineasta Walter Webb para o documentário As vedetes do Brasil (2003), Virgínia Lane "fez uma população flutuante, como a Broadway hoje é para Nova Iorque, aquela população toda que quer ir ver as peças, o pessoal viajava do Brasil todo para ver Virgínia Lane, era um negócio impressionante" (Oliveira Junior; Harazin, 2003, 22:28min).

A vedete, pois, instauraria a ideia de glamour como importância central na construção de imagens e representações de si (Soliva, 2016), característica que será fundamental como estratégia para as vedetes-travestis. Para Soliva (2016), é sob o signo do glamour, conjugado a imagens de cosmopolismo e modernidade, que indivíduos fora da norma heterossexual puderam se inserir em espaços normativos, antes impenetráveis da sociedade. O glamour seria um tipo de "agência entre esses indivíduos, permitindo que habitassem o mundo, reivindicando existência dentro da norma heterossexual" (Soliva, 2016, p.16). As imagens de cosmopolismo e da modernidade estariam ligadas ao gosto,

relacionado à idolatria que eles nutriam pelas divas do cinema norteamericano e do cenário musical brasileiro, sobretudo aquele povoado por artistas considerados mais antigos ou mesmo ultrapassados - como os repertórios melancólicos e dramáticos das cantoras do rádio. Mulheres como Judy Garland, Barbra Streisand, Liza Minnelli, Elizeth Cardoso, Emilinha Borba e outras cantoras e atrizes, ainda que estivessem separadas por décadas umas das outras, eram consideradas por esses homens como símbolos de beleza e de elegância (Soliva, 2016, p. 22-23). 


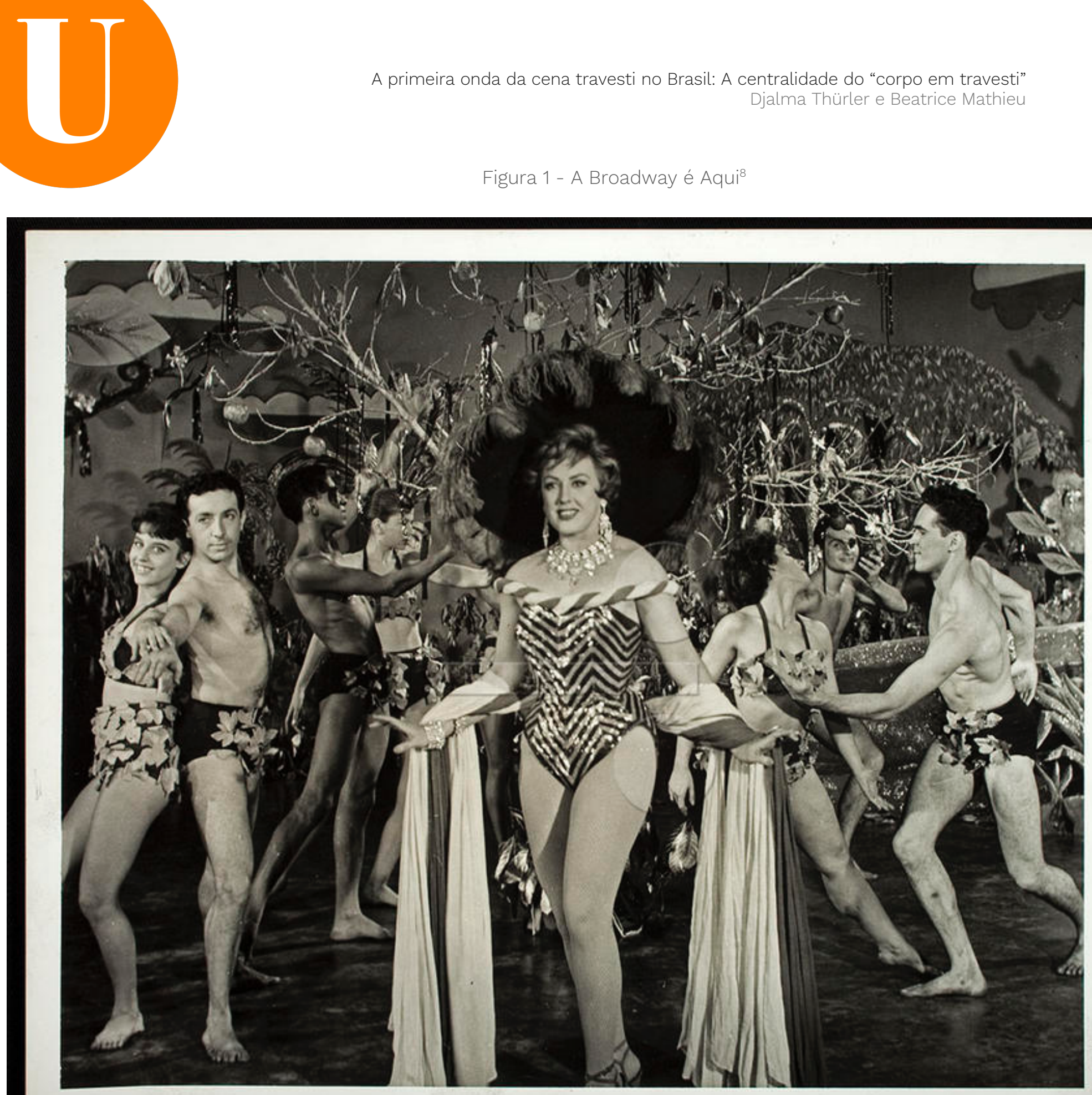


simbólica, através do qual as "travestis" brasileiras experienciaram uma realidade menos violenta e até um considerável reconhecimento, tendo em vista o assédio que sofreram da imprensa" (Soliva, 2016, p.66), ou seja, a curiosidade, mais do que a hostilidade ou o medo, caracterizou a resposta do público brasileiro das Revistas à cena travesti durante essa primeira onda, o que vai contribuir para a proliferação de atores transformistas ocuparem lugares altamente disputados na cadeia cultural do Rio de Janeiro durante a segunda onda.

Nesse sentido, Meneses e Jayo (2018) afirmam sobre Ivaná:

Foi uma performer que se apresentou a um público bastante popular e massificado. Chegou a estrelar papéis femininos em diferentes filmes nas décadas de 1950 e 1960 - como, por exemplo, no longa Mulher de Verdade (Alberto Cavalcanti, 1954), em que contracenou com artistas populares como Inezita Barroso, Adoniran Barbosa e Paulo Vanzolini - o que significava transpor barreiras inimagináveis para a época (Meneses; Jayo, 2018, p.164).

Nessa primeira onda, então, estamos a falar de um "momento da história do Brasil em que as subjetividades, identidades e especificidades "trans" ainda não eram pensadas; não eram dadas condições de serem discutidas. Eram vistas/os todas/os como homossexuais e o ambiente artístico foi um dos espaços em que se podia viver uma possível transgressão" (Lion, 2015, p. 108). Desse contexto, destacamos o trabalho transformista de Aymond e Ivaná10, as imitadoras do belo sexo, as travestis profissionais.

\section{A espetacularização do estranho}

Não tinha esse negócio de peito de verdade.

Era tudo fajuto, mas fazia efeito

(Cintura Fina apud Morando, 2020, p. 55)

Sobre Aymond e seu intérprete, há pouquíssimas informações e muito dispersas (Veras, 2015; Veras, 2017; Morando, 2012, Meneses; Viana, 2016; Cesário,

${ }^{10}$ Foram muitas as grafias encontradas para o nome de Ivaná, neste artigo optamos por essa forma. 
2019). Giovanna Zamith Cesário afirma que ele teria iniciado sua carreira, "um misto de fascínio, mistério e curiosidade” (Cesário, 2019, p.145) no Brasil, em 1925, quando fora contratado por Jardel Jércolis para atuar junto à companhia Tro-lo-ló, mas teria ficado mais conhecido no circuito revisteiro a partir de 1928, quando ao lado de Alda Garrido, Olympio Bastos e Vicente Celestino estrelara a peça "Palácio das Águias" (Cesário, 2019).

É do trabalho de digitalização do Diário da Manhã, disponibilizado pela Companhia Editora de Pernambuco/Cepe, que podemos dizer "que o argentino Aymonino, o Aymond, era um transformista que, em 1938, esteve no Casino Grande Hotel precedido por anúncios como "Aymond, em suas curiosas e brilhantes apresentações - Homem ou mulher?" e "Aymond, artista de dupla personalidade, em apresentações e tipos variados" (Veras, 2015).

Figura 2: Obscuro Fichário dos artistas mundanos ${ }^{11}$

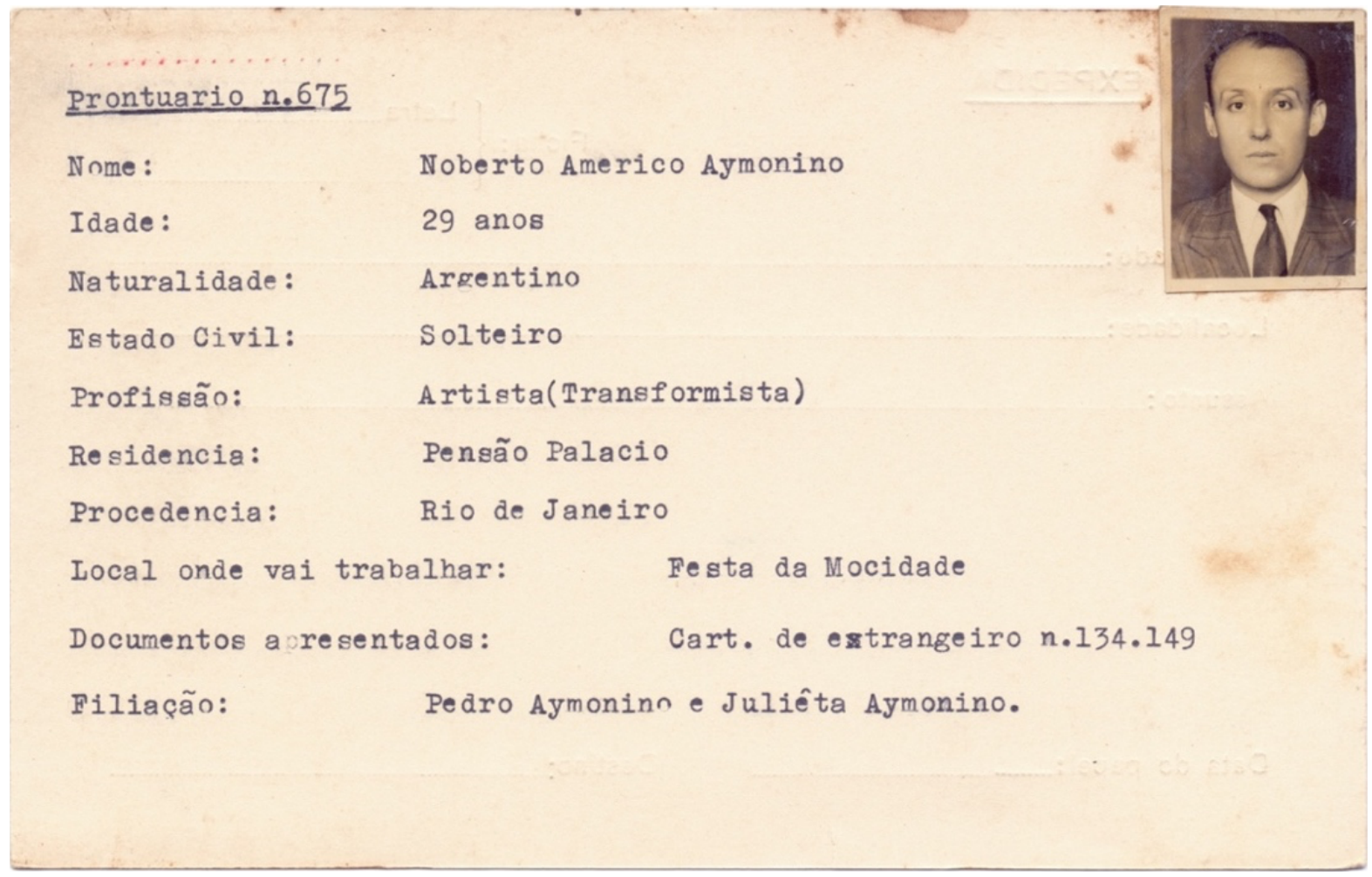

Como dá-se a notar pela ficha consular de qualificação, Aymond era

\footnotetext{
${ }^{11}$ Fonte: http://obscurofichario.com.br/fichario/norberto-americo-aymonino/. Acesso em: 03 jun. 2021.
} 
transformista,

e imitava a voz de cantoras de sucesso mundial com tanta perfeição que recebeu o apelido de "o artista garganta de ouro". Mesmo com a dualidade desse apelido, que poderia suscitar piadas de mal gosto, Noberto tinha boa aceitação junto ao público que reconhecia seu talento de imitador e impressionava-se com sua desenvoltura atuando como personagem feminina. No palco, ele surpreendia tanto por imitar o timbre das diferentes cantoras, como também por ser um homem e ficar irreconhecível ao se vestir "de mulher" (Veras, 2017, p.237).

O destaque à "garganta de ouro" faz referências à qualidade da sua voz, essa assinatura íntima do ator, como pensou Pavis (1999, p.432), e Aymond era muito versátil e competente, "cantava todo o tipo de música: tangos, sambas, operetas; e também cantava coplas para introduzir os personagens da peça, além disso, poderia também apresentar chansonettes nos entreatos” (Cesário, 2019, p.146).

A boa aceitação de Aymonino como transformista que "apresentava pequenos espetáculos antes de exibições cinematográficas imitando artistas da época como a norte-americana Jeanette MacDonald, a espanhola Raquel Meller e a argentina Mercedes Simone" (Meneses; Viana, 2016, p. 273) "não parece ter tido problemas para conseguir emprego" (Veras, 2017, p.238), vivendo fora da marginalidade, com empregos no teatro de revista, também, fora do triângulo cultural do Rio de Janeiro, como atesta Luiz Morando (2012, p.167-168):

Em maio de 1934, o artista Norberto A. Aymonino apresentou show de transformismo para grande público sob o nome artístico de Aymond. [...] Aymond, em sua arte, é Homem e Mulher!". Seus espetáculos garantiram um grande número de pessoas, com sessões esgotadas no único teatro da cidade - o Municipal (futuro Cine Metrópole) - e, posteriormente, nos melhores cinemas (Cine Teatro Brasil, Avenida, Floresta).

Segundo Cesário, Aymond amplia essa geografia de atuação e ainda teria se apresentado por diversos estados brasileiros, em 1933 teria atuado em espetáculos no Rio Grande do Sul e Paraná e, em 1934, 1936 e 1938, o transformista voltaria a se apresentar em São Paulo, Rio de Janeiro e Pernambuco, respectivamente. Ainda segundo Cesário, "o travestido permaneceu se apresentando aqui [no Brasil] até mais ou menos 1945" (Cesário, 2019, p.146). 
Diego Nunes, autor de Cá e lá, o intercâmbio cinematográfico entre Brasil e Portugal, afirma que Ivaná, em entrevista à Revista do Rádio em 29 de julho de 1961 fez questão de lembrar que o pioneiro foi Aymond: "Antes de mim, os brasileiros tiveram ainda Aimo (sic), que apesar da idade avançada, ainda continua a trabalhar. Ele é o verdadeiro pioneiro" (Nunes, 2015, p.159).

Antonio Ricardo Calori de Lion (2015), em Ivaná: a grande dúvida no teatro de revista dos anos 1950 sustenta que foi em 1953 que Walter Pinto trouxe para o Brasil um grupo de artistas para trabalhar na peça de revista intitulada É Fogo Na Jaca, de autoria do próprio Walter Pinto, Freire Júnior e Luiz Iglesias. Com essa troupe de artistas, desembarcara Yvan Vitor Ulisses Monteiro Damião, ator transformista que interpretava e dava vida à Ivaná nos palcos do teatro de revista nos anos 1950.

Yvan era modelo e corista na casa de espetáculos Le Carrouseul, onde Pinto o conheceria. Podemos aferir que essa experiência no Le Carrouseul foi importante na construção da personagem Ivaná, afinal essa casa de shows, desde 1936 e, especialmente a partir dos anos 1950, se notabilizou pelas female impersonators. Foi, também, onde as primeiras grandes estrelas transexuais atuaram, incluindo Coccinelle ${ }^{12}$ (1931-2006) e Bambi13 (1935), que lideraram a crítica nos anos 50 e 1960. O Le Carrouseul, que abriu em 1947 já tinha sido, no início do século XX, em 1901, o Théâtre de la Comédie Mondaine, mas, só em 1990 se transforma no Carrossel de Paris. O Madame Arthur, famoso cabaré pós-guerra inaugurado em 1946, também em Paris, batizado assim em homenagem à canção que Yvette Guilbert, era e, ainda é hoje, importante impersontion club, espaço de experimentações de novas estéticas travestis.

\footnotetext{
${ }^{12}$ Coccinelle nasceu em Paris com o nome de Jacques Charles Dufresnoy a 23 de agosto de 1931. Trabalhou como ator transformista no Madame Arthur e, mais tarde, no Le Carrousel. Em 1958 foi submetida à cirurgia de mudança de sexo em Casablanca, voltando aos palcos e tornando-se a primeira estrela transexual em França. Esses dados, vale destacar, foram retirados de uma longa entrevista, com fotografias, que Coccinelle deu à revista Confidential para a sua edição de setembro de 1962. Fonte: http://transascity.org/files/history/Coccinelle_1962_September_Confidential_Magazine_sm.pdf

${ }^{13}$ Bambi, Marie-Pierre Pruvot, nasceu em Bordj-Ménaïel, subúrbio de Argélia com o nome de Jean-Pierre Pruvot, 11 de Novembro de 1935. Atuou no Le Carrousel durante aproximadamente 20 anos, e apareceu em vários documentários, tais como Costa Azzurra (1959) e 90 Notti em Giro per il Mondo (1963). Enquanto trabalhava como atriz, frequentou a Sorbonne em Paris, tornando-se professora de literatura em 1974. Foi perfilada no filme documentário Bambi, de Sébastien Lifshitz, que ganhou o Prémio Teddy para Melhor Filme Documentário no Festival Internacional de Cinema de Berlim de 2013.
} 
O site Queer Music Heritage, valiosa ferramenta de divulgação de música e cultura LGBT, possui em seus arquivos um instigante programa, como aqueles que eram distribuídos ou vendidos em peças de teatro, mas não tem data, o que dificulta sua localização temporal, embora o próprio site diga que, "best guess, this program is from the early 1960's". Neste programa, com mais de 40 páginas, chama a atenção a galeria de estrelas travestis acompanhadas da respectiva foto do artista em trajes masculinos, como pode-se perceber, nesta foto de Coccinelle:

Figura 3 - Coccinele ${ }^{14}$

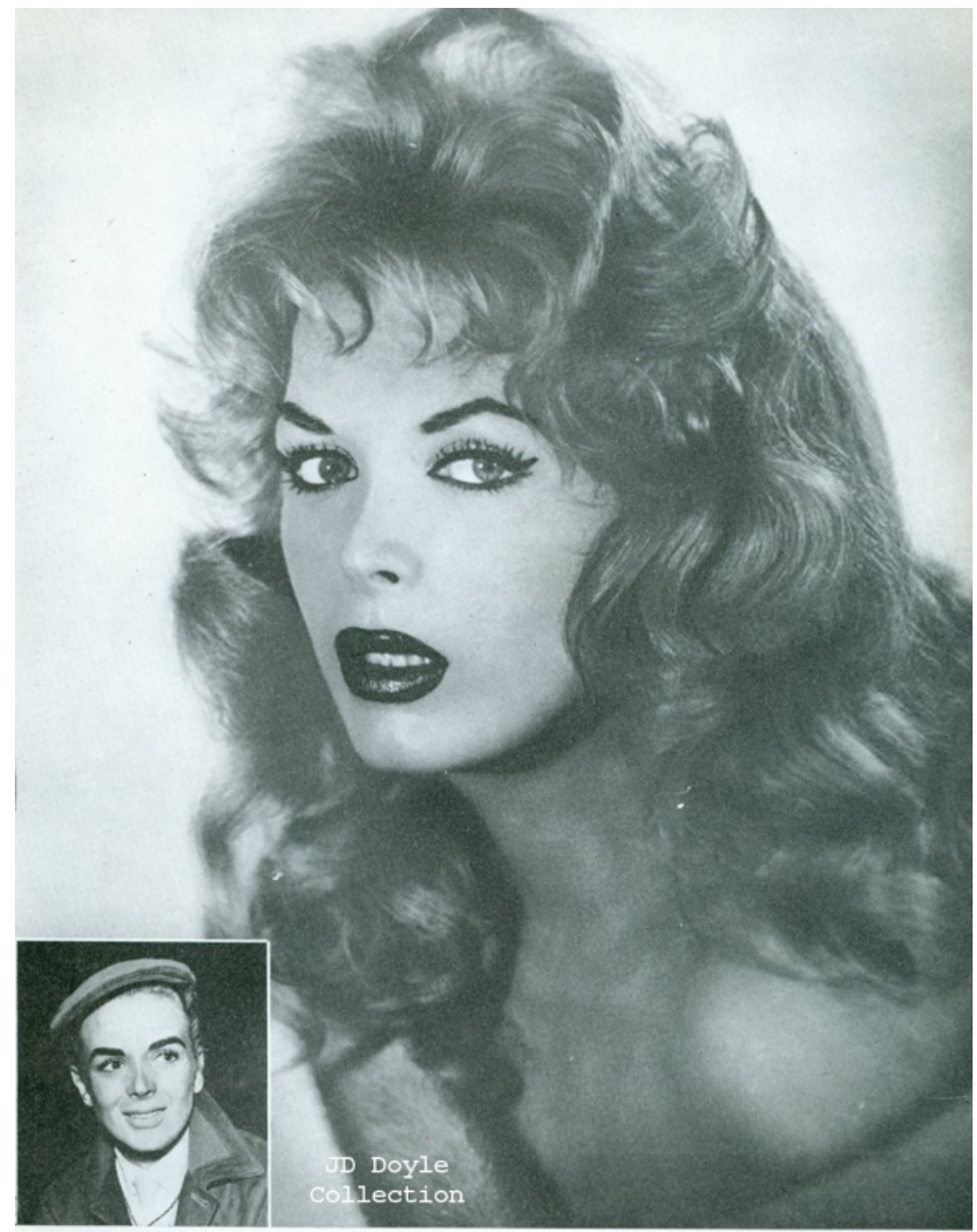


Algumas características eram comuns a esses espaços, lugares engraçados, de alegre provocação, sexys, autênticos e, acima de tudo, um celeiro de talentos, o que justificaria, em 1955, uma impressão de Salomé Parísio (1921-2013) sobre Ivaná:

Ivaná eu conheci no Rio, o Walter Pinto fez um jantar com todo o elenco e nós fomos apresentados. Como rapaz, ele não me impressionou, mas depois, no meio do jantar apareceu vestido de mulher e eu fiquei encantada, ele era linda! No espetáculo ele descia uma escadaria enorme, com vestido longo e saltos altos ainda mais longos. Era uma escada sem tamanho e eu pedi para o Walter que queria fazer igual, e ele disse que eu não conseguiria, então eu chegava mais cedo no teatro e treinava descer a escada, até que um dia eu mostrei para Walter, ele disse 'essa mulher é demônio' e eu passei a fazer o número da escada também (Nunes, 2015, p.164).

Podemos inferir que, além da female impersonators, Ivaná também colaborou para uma certa tecnologia da cena revisteira no Brasil a partir de sua experiência pelos cabarés franceses, pela importação de elementos, como éblouíssemnt, luxe et elegánce, características comuns aos cartazes que anunciavam as atrações transformistas, o que poderíamos aproximar da ideia pensada por Marcia Ochoa (2004), do "talento de ser fabulosa",

las "fabulosas" se conocen a veces como divas o locas. En Venezuela, entre otras cosas, se llaman transformistas, y ellas han transformados mis conceptos de feminidad, poder y marginalidad. No es para romantizarlas: quedemos claros en que ellas viven vidas muy complicadas, como la mayoría de la humanidad, que tienen sus problemas particulares y sociales, y que a veces, como todo el mundo, son discriminatorias, groseras, sexistas, atrevidas, y quién sabe qué más (Ochoa, 2004, p. 242).

Frisa-se que, ao utilizar a expressão "loca", Ochoa o faz no seu sentido mais generoso e lisonjeiro, como uma categoria usada em muitos ambientes gueis, para se referir às pessoas mais ousadas, ou nas palavras de Cecilia Palmeiro, "as loucas são todas aquelas subjetividades minoritárias por serem feminizadas: as bichas, as sapatas, as putas, as feministas - todas aquelas barrocamente femininas" (Palmeiro, 2017, p.202). 
Assim, loucas, fabulosas e glamorosas, as vedetes travestis ainda impressionavam pela destreza e habilidade com que dominavam o palco e a relação com a plateia.

Sobre a identidade do intérprete de Ivaná há ainda muitas dúvidas. Lion (2015), a partir do livro de Diego Nunes (2015), afirma que ele teria nascido em 1933, "filho de pai português e mãe russa, o rapaz nem mesmo era francês, e sim português" (Nunes, Diego, 2015, p. 159, apud Lion, 2015, p. 109), no entanto, localizamos no site do Cabaret Chez Nous Berlin, sua ficha de identificação pela qual, Yvan Monteiro Damião seria mesmo francês e teria nascido em 1935.

\section{REPÚBLICA DOS ESTADOS UNIDOS DO BRASIL} FICHA CONSULAR DE QUALIFICAÇÃO

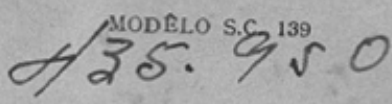

Esta ficha, expedida em duas vias, será entregue à Polícia Maritima e à Imigração no pôrto de destino

Nome por extenso...........MONTEIRO ..DAMIAQ Yvan

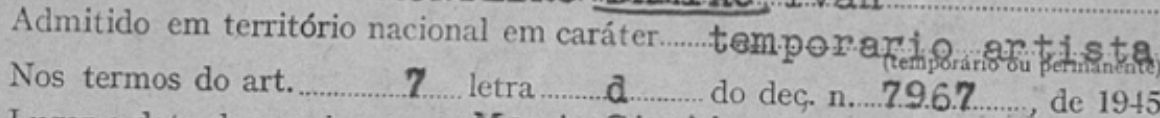

Lugar e data de nascimento Mont St Aignan 20.2 .35

Nacionalidade francesa

Filiação (nome do Pai e da Mãe)....... Yvonne Lebret $>\mathrm{R}$

Resjdência no país de origem. Paris Profissão dansarino

IDADE SEXO

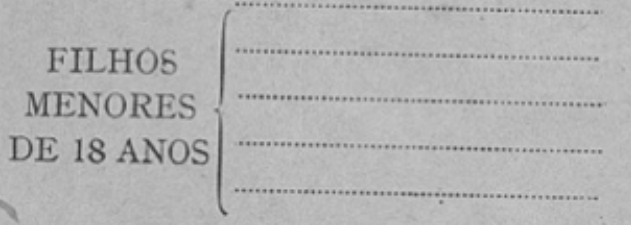

Passaporte n. 28543 expedido pelas autoridades de Pref.Pol.P.Pari visado sob n... $\quad 730$ na data ........28..3.3.5.3.
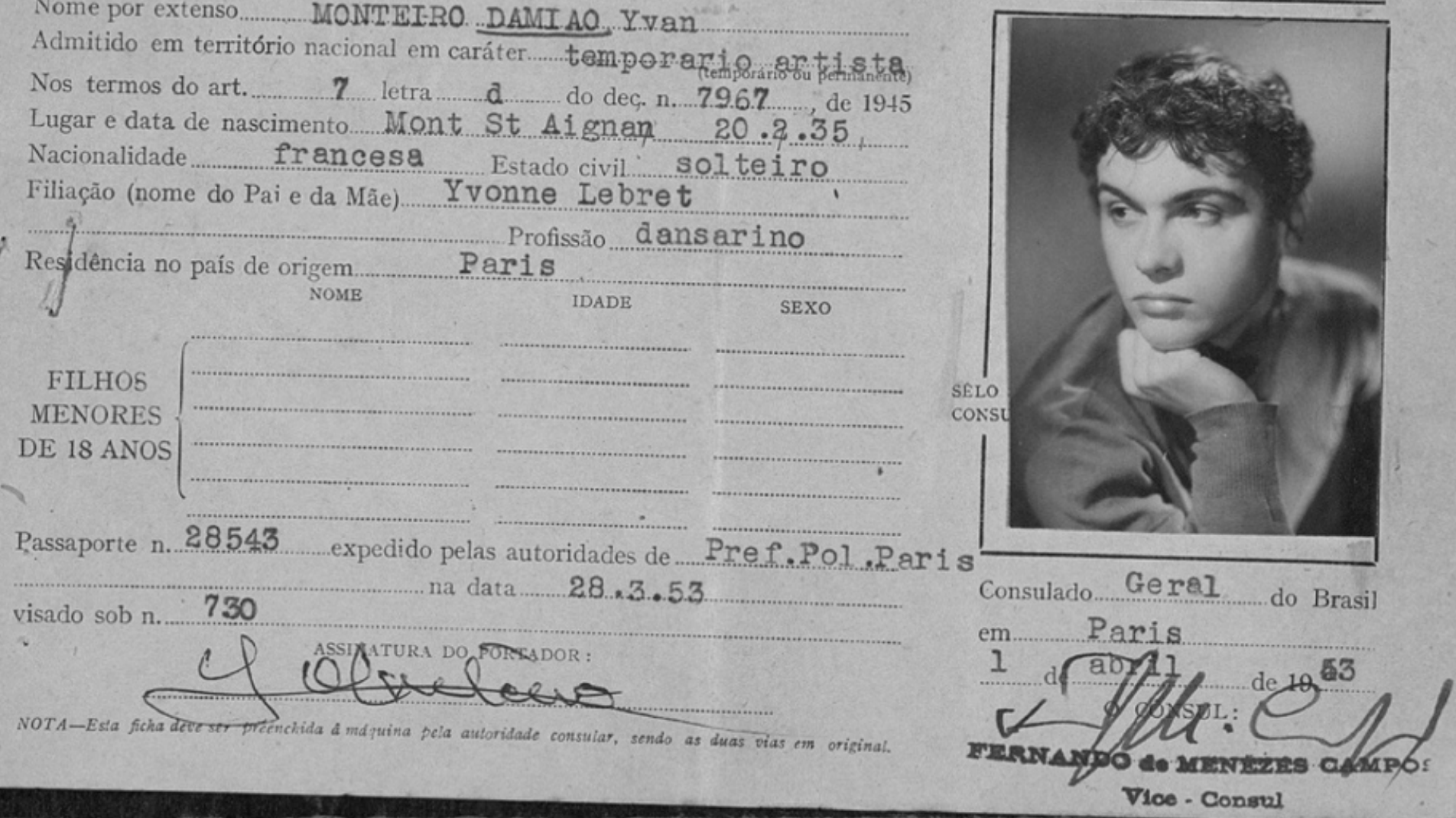

15 Fonte: https://web.facebook.com/media/set/?set=a.539480122851787\&type=3. Acesso em: 23 abr. 2021. 
Outra confusão recorrente é sobre a identidade de gênero de Yvan. Walter Webb, no mesmo As vedetes do Brash (2003), revela que

teve uma coisa interessante, quando o Walter Pinto contratou uma francesa que ele conheceu na Argentina, que não era uma francesa, era um francês, com o nome de Ivana, Ivaná, e lançou esse homem também. $\mathrm{Na}$ mesma época da Virgínia Lane. Só que esse cara, como ele era homem, o primeiro transexual que apareceu no Brasil, a primeira vez que um homem apareceu vestido de mulher com seios não artificiais, seios mesmo, isso foi um negócio incrível que todo aquele reacionarismo brasileiro, o cara deixou de lado: ‘Ah, não vamos ver esse homem?”. E esse homem foi um sucesso enorme, enorme, enorme e, até, parece, deu um ciúme na Virgínia: 'Porra, a vedete aqui sou eu' (Oliveira Junior, Harazin, 2003, 22:47min).

Ou seja, Webb afirma que Ivaná seria uma transexual quando, na verdade, era um ator transformista "apontada como a "primeira travesti' a atuar nos palcos do Brasil de forma não caricata e reconhecida como uma vedete, mas ela não era uma travesti tal como se identifica atualmente" (Lion, 2015, p.115). O que Lion tenta esclarecer e que encontra reverberação em Soliva, é que "a participação de homens 'em travesti' não era novidade no Teatro de Revista” (Soliva, 2016, p.79), nem nos filmes da Atlântida, cujos realizadores, atentos aos elementos propiciadores do riso, não hesitaram em usar o "gênero travesti", popularizado nas personagens vividas por atores como Oscarito, Grande Otelo e Carlos Gil. Ou seja, estamos a falar que "estar em travesti" era, neste tempo, uma estratégia que buscava o riso comum no mundo do trabalho artístico, que tinha um tratamento especial para essa questão, como também o eram o

fazer alguém de bobo; o malogro da vontade; a sátira, a crítica e a paródia literária; a linguagem de baixo calão; a obscenidade; a escatologia; a alteração do estado natural das personagens; o transformismo, principalmente ligado a personagem masculina que se traveste; a quebra da ilusão cênica; à parte, enquanto cumplicidade com o público; o nonsense ou o absurdo; os equívocos; a repetição de palavras, falas ou situações; o duplo sentido; jogo de palavras; a mentira (Bender, 1996, p.4142),

muitas dessas, utilizadas no interior da própria estética revisteira. Vejam o exemplo a seguir, do uso do duplo sentido, extraído do documentário As vedetes do Brasil (2003), descrito pela ex-vedete Siwa: 


\begin{abstract}
Número de plateia era a vedete que vinha numa passarela - a orquestra ficava no fosso -, o palco [aponta para traz] e, depois, tinha avançado, uma passarela em que as vedetes e os personagens principais se dirigiam diretamente para o público. Eu vinha vestida de colegial com uma gaiolinha na mão. Então eu dizia: "Puxa, o Manezinho é um bruto, ele tanto falou, tanto pediu: me dá teu pixoxó, me dá teu pixoxó, que eu dei o pixoxó da minha gaiolinha, agora a minha gaiolinha está vazia e eu precisava achar um pixozinho para colocar dentro da gaiola”. Então a vedete, como vinha na frente, tinha esse diálogo mais íntimo com a público. "Ah, você tem? Então mostra!" Aí era aquela gargalhada. "Não, agora não posso". "Ah, vai ver que ele não tem". Era outra gargalhada. "E o senhor tem?" Aí a senhora, a esposa, cutucava: "Fala, fala". "Tenho!" "Ah, a senhora conhece o pixoxó dele?" Ah, nossa [a plateia] vinha abaixo (Oliveira Junior, Harazin, 2003, 06:16min).
\end{abstract}

Quanto à Ivaná, o que distinguiria o seu travestimento dos outros tantos próprios desse gênero popular, era o resultado alcançado, "sua figura não era calcada na caricatura, mas sim no glamour típico das divas cinematográficas do período, e era construída com a clara intenção de 'passar por' mulher' (Meneses; Jayo, 2018, p.163): "cantava como mulher, trajava-se como mulher e apresentava o 'charme' e o 'sexy' das grandes francesas das ‘boites' cariocas” (Serra, 1953 apud Lion, 2016, p. 12), por isso é possível afirmar que foi a "perfeita imitação do feminino que materializava" (Soliva, 2016, p.79) a ilusão de heternormatividade que “confundiu o público, os religiosos e os agentes da ordem” (Veras, 2017, p.237), ou seja, a qualidade do travestimento de Ivaná reforçava a ideia do alto profissionalismo que caracterizava o trabalho dessas transformistas (Newton, 2016), ao mesmo tempo em que se afastava do que pensava Tewksbury (1993), de que as female impersonators eram homens biológicos que atuavam como mulheres perante uma audiência que sabia que eram homens. Fazer-se travesti, neste contexto, estaria relacionado à ambivalência do travestismo discutido por Butler (2002, 2019) e, nesse sentido, o "travestismo é subversivo na medida em que reflete a estrutura imitativa pelo qual o gênero hegemônico é produzido e contesta a afirmação da heterossexualidade quanto a seu caráter natural e original" (Butler, 2019, p. 216). 
Figura 6 - Ivaná e Eloina ${ }^{16}$

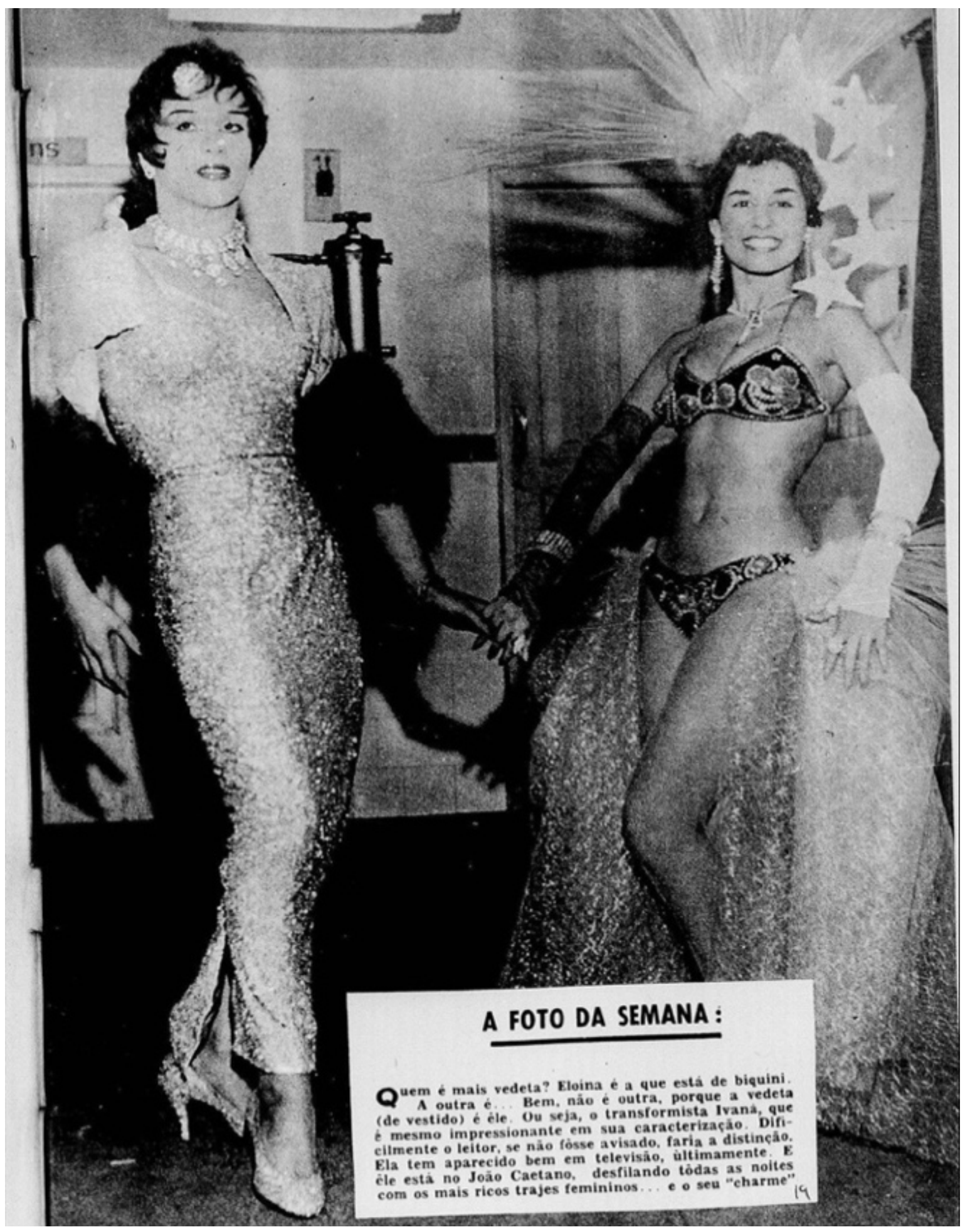

Quando o destaque da matéria sobre a atuação de Ivaná ao lado da vedete

${ }^{16}$ Fonte: https://web.facebook.com/media/set/?set=a.539480122851787\&type=3. Acesso em: 23 abr. 2021. 
Eloina, na revista É tudo Juju-Frufru (Nunes, 2015), alerta que dificilmente o leitor faria a distinção de que ela é, na verdade, ele, não deixa de ser uma operação simbólica, movida pelo pânico homossexual, para criar "um alívio ritual para uma economia heterossexual” (Butler, 2019, p.217), alertando o público e afirmar a naturalidade da heterossexualidade, sua originalidade e normalidade (Butler, 2002, 2019).

Desse modo, as performances, tanto de Aymond quanto de Ivaná, não estariam associadas ao que Martins (2017), recuperando Butler (2002), chamaria de "travestilidade doméstica", aquela que ocorre quando a cultura cisheteropatriarcal se apropria da travestilidade para reforçar as normas de gênero dominantes através do estigma, riso e escracho, delimitando as fronteiras entre o normal e o abjeto, como foram algumas interpretações clássicas, talvez,

a encenação mais famosa de Grande Otelo vestido com roupas femininas
foi na cena que se tornou histórica para o cinema brasileiro com Oscarito
no filme "Carnaval no Fogo", de 1949, quando ele parodiou o texto da
conversa na sacada entre Romeu e Julieta de Shakespeare. Apesar das
múltiplas aparições travestido de mulher, ele não era considerado
homossexual, mas exótico, porque, na verdade, fazia piada com os
afeminados, ridicularizando sua personagem para zombar dos homens
que não se comportavam como se julgava adequado (Veras, 2017, p.237).

Queremos, à guisa de conclusão, afirmar que a cena travesti da primeira onda e a construção da feminilidade verossímil - nos casos de Aymond e Ivaná , entendida enquanto performance artística, troca simbólica, denuncia de forma escancarada que o gênero é apenas uma construção, um arremedo de natureza, como pensou Segato (2018), um conjunto de características, qualidades, papéis, maneirismos, e comportamentos que são ditados pela cultura dominante, que regula a interação social e o significado simbólico entre aqueles que atuam e aqueles que assistem. Quando Aymond e Ivaná rasuram os retratos de gênero esperados, a ideia de que para sermos homens ou mulheres só devemos considerar o que não devemos ser - o oposto (Schacht, 2002), estão a criar e a realizar ativamente um gênero diferente do seu sexo biológico, quebrando conscientemente a cartilha da cultura de gênero dominante. 
Considerando o que foi exposto, destacamos a contribuição de artistas como Aymond e Ivaná para a construção estética dessa primeira onda da cena travesti, através de alguns elementos, como a glamourização do feminino, a partir da presença colorida da vedete e o seu star appeal, que seriam as aptidões para a desenvoltura com a linguagem revisteira; altas doses da "sensibilidade gay", traduzidas em elementos do camp, como a diversão, o humor, o artifício, a ostentação, a superficialidade e a elegância, além da altíssima teatralidade de seus gestos e, claro, saber descer e subir escadas com saltos altíssimos.

\section{Referências}

ABREU, Silvio de. Apresentação. In: VENEZIANO, N. As grandes vedetes de Brasil. São Paulo: Imprensa Oficial do Estado de São Paulo; IMESP, p. 11-12, 2010.

ANTUNES, Delson. Fora do Sério: Um panorama do Teatro de Revista no Brasil. Rio de Janeiro: Funarte, 2002.

AUGUSTO, Sérgio. Este mundo é um pandeiro. São Paulo: Cinemateca Brasileira; Companhia das Letras, 1989.

BAGLALI, Beatriz. Pagliarini. A diferença trans no gênero para além da patologização. Periódicus: Revista de estudos indisciplinares em gêneros e sexualidades. Salvador, n. 5, v. 1, maio-out., 2016.

BENDER, Ivo. Comédia e riso: uma poética do teatro cômico. Porto Alegre: Ed. UFRGS; Ed. PUCRS, 1996.

BORTOLOZZI, Remom Matheus. A Arte Transformista Brasileira: Rotas para uma genealogia decolonial. Quaderns de Psicología, Barcelona, v. 17, n. 3, p.123-134, 2015.

BUTLER, Judith. Cuerpos que inportan: sobre los limites materiales y discursivos del "sexo". Buenos Aires: Paidós, 2002.

BUTLER, Judith. Corpos que importam: os limites discursivos do sexo. São Paulo: Edições n-1, 2019.

CESÁRIO, Giovanna Zamith. Aymond, um ruidoso sucesso: a trajetória do travestido argentino no teatro de revista brasileiro. Arteriais, Belém, v.5, n.9, 2019.

COLLAÇO, Vera. Entre telões e cortinas: a féerie cenográfica do musical revisteiro. O Percevejo, Rio de Janeiro, v. 03, n. 02, jan.-jul., p. 1-26, 2012. 
DIVINAS DIVAS. Direção: Leandra Leal. 2017 (110min.)

DZI CROQUETTES. Direção: Tatiana Issa e Raphael Alvarez, 110 min, 2009.

FREITAS, Nanci de. A personagem-tipo na revista de Walter Pinto: configuração e dissolução. Textos escolhidos de cultura e arte populares, Rio de Janeiro, v.12, n.1, p. 119-142, mai. 2015.

GAULTIER, Jorge. UFSB cancela matrícula de estudante de Medicina por suspeita de fraude na cota para trans: "me mataram”. Jornal Correio, Me Salte, 14 dez. 2020. In: https://blogs.correio24horas.com.br/mesalte/ufsb-cancela-matriculade-estudante-de-medicina-por-suspeita-de-fraude-na-cota-para-trans-memataram/. Acesso em: 15 dez. 2020.

LAMPIÃO DA ESQUINA. Direção: Lívia Perez. 82 min, 2016.

LANS, Letícia. O Corpo Da Roupa: A pessoa transgênera entre a transgressão e a conformidade com as normas de gênero. 2014. Dissertação (Mestrado em Sociologia) - Universidade Federal do Paraná, Curitiba, 2014.

LION, A. R. Ivaná: a grande dúvida do teatro de revista dos anos 50. Revista de Historia, São Paulo v. 7, n. 14, jul.-dez, p. 102-120, 2015.

LION, Antonio Ricardo Calori de. É fogo na jaca: performance drag queen no teatro de revista dos anos 1950. 23으 Encontro Estadual De História, Assis. Anais eletrônicos, UNESP, 2016. Disponível em: <http://www.encontro2016.sp.anpuh. org., São Paulo.

MARQUES, Daniel. Teatro de intervenção: um resgate necessário ( $O$ teatro de revista e a política). Trans/Form/Ação, v.24 no.1, p. 41-46, 2001.

MENESES, Emerson Silva.; JAYO, Martin. Presença travesti e mediação sociocultural nos palcos brasileiros: uma periodização histórica. Extraprensa. v. 11, n. 2, (jan./jun., p. 158 - 174, 2018.

MENESES, Emerson Silva.; VIANA, Fausto. Moda, vestuário e traje de cena: a passabilidade trans no teatro e no cinema Fashion. Anais do III Congresso Internacional de Memória, Design e Moda, p. 268-282, 2016.

MEU AMIGO CLÁUDIA. Direção: Dácio Pinheiro. Produção: Dácio Pinheiro, Alexandra Chalabi, Biba Wedesheim, Chica Mendonça, Daniel Soro, Mariana Guerra. Festival Filmes (87 min.), 2009, cor.

MORANDO, Luiz. "Miloca que virou David": intersexualidade em Belo Horizonte (1917-1939). Bagoas, v. 6, n. 8, p. 147-170l, 2012.

NEWTON, Esther. Mother Camp: Un estudio de los transformistas femeninos em los Estados Unidos. Trad. María José Belbel Bullejos; Paloma Uría. Ed. María José Belbel Bullejos, Madrid, 2016. 
NUNES, Diego. Cá e Lá: o intercâmbio cinematográfico entre Brasil e Portugal. São Paulo: Matarazzo, 2015.

OLIVEIRA JUNIOR, Dimas; HARAZIM, Felipe. As Vedetes do Brasil. (Documentário). Realização: WeDo Comunicação, Rede STV SESC SENAC DE TELEVISÃO (2003).

PAIVA, Salvyano Cavalcanti de. Viva o Rebolado!: vida e morte do teatro de revista brasileiro. Rio de Janeiro: Nova Fronteira, 1991.

PAVIS, Patrice. Dicionário de Teatro. Trad. Jacó Guinsburg; Maria Lúcia Pereira. São Paulo: Perspectiva, 1999.

POLLAK, Michael. Memória, Esquecimento, Silêncio. Revista Estudos Históricos. Rio de Janeiro, v 2, n.3, p. 3-15, 1989.

QUEER MUSIC HERITAGE: In: https://www.queermusicheritage.com/femlac2.html, s/a.

REBELLO, Luiz Francisco. História do Teatro de Revista em Portugal. Vol. I Da Regeneração à República. Lisbon: Don Quixote, 1984.

RODOVAlHO, Amara Moira. O cis pelo trans. Estudos Feministas, Florianópolis, 25(1): 422, jan.-abr., 2017.

SÃO PAULO EM HI-FI. Direção: Lufe Steffen. 2016 (100 min

SAROLDI, Luiz. Carlos.; MOREIRA, Sônia Virgínia. Rádio Nacional: Brasil em sintonia. Rio de Janeiro: Jorge Zahar Ed., 2005.

SCHACHT, Steven. Lesbian Drag Kings and the Feminine Embodiment of the Masculine. The Journal of Homosexuality, n. 43 (3), p. 75-98, 2002.

SEGATO, Rita. Contra-pedagogías de la crueldade. Cidad Autónoma de Buenos Aires: Prometeo Libros, 2018.

SOLIVA, Thiago Barcelos. Sob o Símbolo Do Glamour: Um estudo sobre homossexualidades, resistência e mudança social. 2016. Tese (Doutorado em Sociologia) - Instituto de Filosofia e Ciências Sociais, Universidade Federal do Rio de Janeiro, Rio de Janeiro, 2016.

TEWSKBURY, Richard. Men Performing as Women: Explorations in the World of Female Impersonators. Sociological Spectrum, n. 13, p. 465-486, 1993.

VENEZIANO, Neyde. O teatro de Revista. In: BRANDÃO, T. O teatro através da História. Volume II: O teatro brasileiro. Rio de Janeiro: CCBB; Entourage Produções Artísticas. 1994. p. 139-156. 
VENEZIANO, Neyde. As grandes vedetes de Brasil. São Paulo: Imprensa Oficial do Estado de São Paulo; IMESP, 2010.

VENEZIANO, Neyde. O sistema vedete. Repertório, Salvador, ㄲo 17, p. 58-70, 2011.

VERAS, Flávia Ribeiro. "Fábricas da Alegria": O mercado de diversões e a organização do trabalho artístico no Rio de Janeiro e Buenos Aires (1918 - 1945). 2017. Tese (Doutorado em História) - Fundação Getúlio Vargas (FGV), 2017.

VERAS, Luciana. Os que fogem aos padrões. Fonte: Revista Continente: https://www.revistacontinente.com.br/edicoes/179/os-que-fugiam-aos-padroes, 2015. Acesso em: 11 de dez. 2020).

THÜRLER, Djalma; NUNES, Ana Lucia; ROMERO, Dani. Drags satélites: experiência queer em pesquisa e extensão no ensino universitário. PORTO, C.; ROSA, F. TONNETTI, (Org.) Fronteiras e interfaces da comunicação científica. Salvador: EDUFBA, 2016.

TREVISAN, João Silvério. Devassos no paraíso. Rio de Janeiro: Ed. Record, 2007.

TRANSAS CITY. http://transascity.org/history/.s/a.

Recebido em: 13/06/2021

Aprovado em: 12/08/2021 